\title{
Processo nacional de avaliação do rendimento escolar: tema esquecido entre os Sistemas Municipais de Ensino
}

- Flávia Obino Corrêa Werle*

Adriane Brill Thum**

Alenis Cleusa de Andrade ${ }^{* * * *}$

\section{Resumo}

0 trabalho discute o panorama de municípios do Rio Grande do Sul que criaram Sistemas Municipais de Ensino (SME), analisando como e até que ponto essa legislação acolhe o processo nacional de avaliação do rendimento escolar do ensino fundamental o qual deverá, pela Lei 9394/96, processar-se mediante a colaboração dos sistemas de ensino. Analisa o conjunto das leis de SME apresentando mapas e gráficos da sua distribuição no estado e das que referem a avaliação externa de larga escala. Conclui-se que estas leis não expressam adesão da instância municipal ao sistema nacional de avaliação da educação básica. Este distanciamento do poder municipal face a propostas da União quanto a avaliação externa sugere mecanismos de imposição e não de colaboração entre as instancias de governo.

Palavras-chave: Avaliação da educação. Políticas educativas. Sistema municipal de ensino

\section{National process of school performance evaluation: a forgotten topic among the municipal educational systems Abstract}

This work discusses municipalities prospect of Rio Grande do Sul which have created Municipal Systems of Education (SME), analyzing how and until what point that legislation accepts the national trial of the school performance evaluation of the elementary education that must, according to the Law 9394/ 96, happen with the collaboration of educational systems. It analyzes the set of SME's laws presenting maps and graphs of their distribution in the state and those which are related to the wide scale external evaluation. It was concluded

Doutora em Educação, professora do PPG Educação da Universidade do Vale do Rio dos Sinos (UNISINOS); Coordenadora do Projeto Gestão Democrática e Qualidade da Educação Básica, vinculado ao Observatório de Educação, apoio INEP/ CAPES, do qual este artigo decorre. E-mail: flaviaw2008@gmail.com

“. Especialista em Interpretação de Imagens Orbitais e Sub-orbitais; Mestre em Engenharia Florestal; Professora da UNISINOS. E-mail: adrianebt@unisinos.br

-’. Licenciada em Matemática; Mestranda em Educação pela UNISINOS. E-mail: alenisb@yahoo.com.br

Ensaio: aval. pol. públ. Educ., Rio de Janeiro, v. 17, n. 64, p. 397-420, jul./set. 2009 
that these laws do not express adhesion of the municipal instance to the national system of evaluation of the basic education. This distance of the SME laws shows that the proposals of the Federal Government related to the external evaluation of schools suggests mechanisms of imposition and not of contribution between the government instances.

Keywords: Educational assessment. Educational policies. Municipal system of education

\section{Proceso nacional de evaluación del rendimiento escolar: tema olvidado entre los Sistemas Municipales de Enseñanza Resumen}

Ese artículo discute el panorama de municipios de Rio Grande do Sul que criaran Sistemas Municipales de Enseñanza (SME), analizando como y asta que punto esa legislación acoge el proceso nacional de evaluación del rendimiento escolar de la enseñanza fundamental que deberá, por la Ley 9394/96, procesarse mediante la colaboración de los sistemas de enseñanza. Analiza el conjunto de las leyes de SME presentando mapas y gráficos de su distribución por el Estado y de las que se refieren a la evaluación externa de larga escala. Se concluye que estas leyes no expresan adhesión de la instancia municipal al sistema nacional de evaluación de la educación básica. Este distanciamiento del poder municipal delante las propuestas del Estado cuanto a la evaluación externa sugiere mecanismos de imposición y no de colaboración entre las instancias de gobierno.

Palabras clave: Evaluación de la educación. Políticas educativas. Sistema municipal de enseñanza.

0 estudo focaliza políticas educacionais de âmbito municipal, especificamente as leis que criam os Sistemas Municipais de Ensino. É uma produção decorrente do projeto ${ }^{1}$ de pesquisa Gestão Democrática e Qualidade da Educação Básica que, dentre outras ações, estuda estas leis municipais, analisando-as no sentido de construir/identificar indicadores de gestão democrática e compreender a relação destes, com o desempenho dos alunos, tendo em vista resultados obtidos na Prova Brasil. 0 presente texto apresenta uma parte desta pesquisa, focalizando as leis de Sistema Municipal de Ensino (SME) no que se refere à temática da avaliação de larga escala da educação básica.

\footnotetext{
10 projeto de pesquisa Gestão Democrática e qualidade da educação básica, vinculado ao Observatório de Educação INEP/CAPES, dá continuidade à pesquisa anterior designada Mapa dos Sistemas Municipais de Ensino. A pesquisa atual analisa as leis municipais de educação, organizando-as preliminarmente em um Banco de Dados. Estas pesquisas contaram, na articulação com os municípios, com a colaboração da Federação das Associações de Municipios do Rio Grande do Sul ( FAMURS), colaboração esta firmada em convênio assinado em 14 de dezembro de 2004, entre UNISINOS e FAMURS. De parte da Famurs muito colaborou para a efetivação do convenio a professora Tânia Kirsch, diretora do Departamento de Educação e outros técnicos da entidade. 0 Conselho Estadual de Educação tem fornecido também informações valiosas e atualizadas acerca das leis de sistema municipal de ensino possibilitando acompanhar o processo continuo de criação de SME pelos municipios do RS. Vários bolsistas de iniciação cientifica colaboraram em diversas fases do projeto, dentre eles, Sheila Eskeff Konarsewski, Cinthia Colao Merlo, Marzane Tarocco, Alenis Cleusa de Andrade.
}

Ensaio: aval. pol. públ. Educ., Rio de Janeiro, v. 17, n. 64, p. 397-420, jul./set. 2009 
0 texto estrutura-se apresentando considerações teóricas sobre o papel da legislação na estruturação da educação municipal, os sistemas de ensino como um fator importante de manifestação da organização do poder local para, a seguir, apresentar o quantitativo de municípios do estado que criaram SME. Segue problematizando acerca do diferencial de matrículas entre as redes municipais e as implicações de generalizar a criação de $S M E$, pois há municípios muito pequenos em número de matrículas públicas na educação básica, enquanto outros contam com numerosas matrículas. Por fim descreve e analisa, como em municípios que criaram SME, as referências acerca do tema avaliação externa e de larga escala da educação básica. Considera que, se a Constituição de 1988 (BRASIL, 2003) e a Lei nº. 9.394 (BRASIL, 1996), abriram a possibilidade de maior autonomia para a instância municipal, o exercício desta autonomia pela criação de SME constitui-se em um contexto no qual o sistema de avaliação externa e de larga escala da educação básica poderá ser articulado e desenvolvido. Este estudo não acompanha o processamento e as rearticulações pelas quais passam as leis de SME em cada município, nem as nuances que as mesmas adquirem em cada espaço de prática da educação municipal, mas toma o texto de criação de SME e, a partir dele, analisa como a avaliação de larga escala é proposta e articulada no âmbito desta instância. Compreende-se que tempos e espaços delimitam e articulam especificamente a organização social e política da educação municipal. Em decorrência desta compreensão este estudo prevê a apresentação dos dados em formato analítico-interpretativo e de mapas e gráficos que quantificam e localizam as questões estudadas.

\section{Metodologia}

As políticas de educação básica municipais distribuem-se conforme articulações locais e interesses político-administrativos situados espacialmente, com o que tempo e espaço são elementos importantes na sua análise. Uma forma de expressar esta compreensão teórico-metodológica é através da visão sintética e prenhe de informações que os mapas oferecem ao permitir identificar a distribuição espacial dos elementos analisados.

A pesquisa envolveu, num primeiro momento, a coleta e organizaçao de leis de sistemas municipais de ensino bem como sua análise, considerando, dentre várias temáticas, a da avaliação externa de larga escala. Num segundo momento, procedeu à criação dos mapas temáticos, cuja construção constituiu várias etapas, algumas delas concomitantes.

Este segundo momento desdobrou-se, numa etapa inicial que consistiu na organização de dados brutos quais sejam, mapas de Municípios do Estado do Rio Grande do Sul (RS), escala 1:2.500.000, formato shapefile, tendo como fonte 0 Instituto Brasileiro de Geografia e Estatística (IBGE), de 2005, bem como planiIhas Excel e Access, organizadas pela equipe de pesquisa, com informações sobre

Ensaio: aval. pol. públ. Educ., Rio de Janeiro, v. 17, n. 64, p. 397-420, jul./set. 2009 
cada município do RS, ordenados alfabeticamente, e a indicação de existência ou não de SME associadas a categorias analíticas da pesquisa. A escolha dos softwares utilizados foi a seguinte etapa para a qual se utilizou como critérios a possibilidade de apresentação e cruzamento de dados necessários aos objetivos da pesquisa e a compatibilidade de uso entre os softwares - ArcGIS arcView 9.2; Microsoft Excel 2003 e Microsoft Access 2003. No software ArcGIS foram importados o mapa do estado do RS, georeferenciado no sistema de referencia WGS-84, com as divisas municipais e as tabelas com os dados da pesquisa. No ArcGIS fez-se uma conexão entre os polígonos que representam cada município com suas respectivas informações nas tabelas, usando como chave do relacionamento o nome do município. Por fim, foi possivel dentro do ArcGis gerar mapas temáticos através da relação cruzada de variáveis. Dessa relação foi possivel extrair uma simbologia para cada mapa do RS.

\section{Sistemas Municipais de Ensino no Rio Grande do Sul}

Os textos de leis são entendidos como uma face das políticas e uma cristalização de interesses resultantes de inúmeros processos de negociação, disputa e resignificação. As leis, por serem elementos do "mundo constitucional" (FREY, 2000) e do contexto das politicas públicas, expressam processos estruturadores intencionados num determinado espaço e momento histórico. Por comporem uma estrutura prevista e desejável e pela compreensão de que os textos das leis de SME constituem uma política estabilizadora da institucionalização da educação no âmbito dos Municípios, este estudo se debruça sobre os textos das leis de SME. Entende-se política estruturadora com Frey (2000) como aquela que define instituições, processos, normatiza elementos referentes a uma área de ação, no caso a educação em um municipio. 0 SME abrange muito mais do que apenas a rede de escolas mantidas pelo governo municipal, pois inclui organismos e ações de articulação do conjunto de forças sociais e políticas, de escolas estaduais e particulares existentes na comunidade.

Os textos das leis condicionam e limitam a configuração institucional da educação e a ação dos educadores, mas também oferecem oportunidades de criação de novos caminhos e de processos de interação social. Não perduram indefinidamente, mas apenas enquanto outros interesses e disputas não se fortalecerem, articularem e assumirem posições em disputa com elementos já estabelecidos na legislação. Por outro lado, aqueles que atuam em diferentes niveis da educação e que se movimentam nos espaços regrados pelas leis inserem nuances diferenciadas na mediação entre as práticas, as limitações, os recursos disponiveis e as normas legais.

Nelly Stromquist (1996), Lopes (2004), Mainardes (2006) com base em Stephen Ball $(1995,1998,2001)$ discutem as políticas educacionais como dinâmicas, temporal e socialmente estruturadas, perpassadas por contextos diferenciados, desvelando sua grande complexidade. Refletem que as políticas não podem ser percebi-

Ensaio: aval. pol. públ. Educ., Rio de Janeiro, v. 17, n. 64, p. 397-420, jul./set. 2009 
das como tarefas que pertencem a outras pessoas, em geral situadas na administração do Estado, os abstratos legisladores de que fala Cunha (1981). Consideram que os professores não são receptáculos de diretrizes políticas e que as políticas não são um processo formal de cumprimento de regras e normativas. Ao contrário, as políticas ocorrem por processos diferenciados, articulados diversificadamente em níveis, instituições, grupos e espaços os quais desenvolvem processos reprodutivos mas também de infidelidade normativa (LIMA, 2001). Concordando com Lima, Nelly Stromquist (1996, p. 28) afirma a possibilidade das políticas bem como a ação que sobre elas têm os diferentes atores:

Contrariando a visão que postula a sequência linear na formulação de uma política pública, começamos a aprender que, pelo fato de vários atores estarem implicados no processo - de políticos, a burocratas e a equipes escolares essas pessoas inserem certas modificações nas políticas públicas, alterações que tem origem em sua interpretação sobre as politicas públicas em si e na extensão de sua concordância em relação a elas.

A autora assinala que as políticas públicas podem adquirir múltiplas formas (planos, projetos, sistemas de avaliação), dentre as quais a de texto legal, e que diferentes atores estão nelas implicados desde a fase da formulação, explicitação legal e implementação. Esses atores delas se reapropriam, rearticulando-as, inserindo-Ihes modificações e interpretações. Os textos legais são, pois, resultados de interações, de disputas, e a força de outras articulações e interesses, podem modificá-los, revisá-los, ampliá-los e suprimi-los. Ou seja, com Ball (2001, p. 102) entendemos que as políticas são "retrabalhadas, aperfeiçoadas, ensaiadas, crivadas de nuances e moduladas através de complexos processos de influência, produção e disseminação de textos".

A instituição de sistemas de ensino², a partir dos municípios é, desde a Constituição Federal, uma possibilidade, reforçada na Lei de Diretrizes e Bases (BRASIL, 1996). Entende-se que o SME é uma forma peculiar das forças sociais locais interpretarem e inscreverem-se na educação brasileira, explicitando traços característicos e de identidade próprios, incluindo, e, não exclusivamente centrando, a ação na criação de estruturas institucionais (órgãos normativos e executivos), focalizando a educação escolar em especial a educação básica. Tal possibilidade precisa explicitarse em lei e sua formulação pressupõe o exercício de prática de autonomia e responsabilização dos atores locais (executivo, legislativo municipal, Conselho Municipal de Educação (CME), sindicato e associação de docentes, escolas públicas, escolas privadas, pais, alunos e cidadãos da localidade).

\footnotetext{
${ }^{2}$ Para o Conselho Nacional de Educação (2002) sistema de ensino é o "conjunto de campos de competências e atribuições voltadas para o desenvolvimento da educação escolar que se materializam em instituições, órgãos executivos e normativos, recursos e meios articulados pelo poder público competente abertos ao regime de colaboração e respeitadas as normas gerais vigentes".
}

Ensaio: aval. pol. públ. Educ., Rio de Janeiro, v. 17, n. 64, p. 397-420, jul./set. 2009 
0 estado do RS tem-se mostrado ativo e interessado na constituição de sistemas municipais de educação, desde o final dos anos noventa. Contabiliza, até junho de 2007, 184 municípios com SME próprio, o que representa 37\% do total de seus 496 município. Até o ano de 2000, havia no RS, 51 municípios com SME, sendo que 10 foram criados ao longo do ano 2000. Observa-se a diferença frente a Minas Gerais, por exemplo, que tem 853 municípios e apenas 8 deles haviam criado SME até 0 ano de 2000 (TEIXEIRA, 2004). 0 RS comparativamente a Minas Gerais, portanto, tem mostrado iniciativa e interesse na constituição de SME e avançado na criação de sistemas próprios para articular a educação municipal. 0 processo não se iniciou na capital do estado, mas assume posição e marca presença em diferentes regiões do estado. 0 Mapa 1 apresenta a localização de municípios que criaram Sistema Municipal de Ensino no RS, no período de janeiro de 1997 a junho de 2007, indicando que o movimento de criar SME não está localizado nesta ou naquela região do estado, mas distribuído mais ou menos equitativamente.

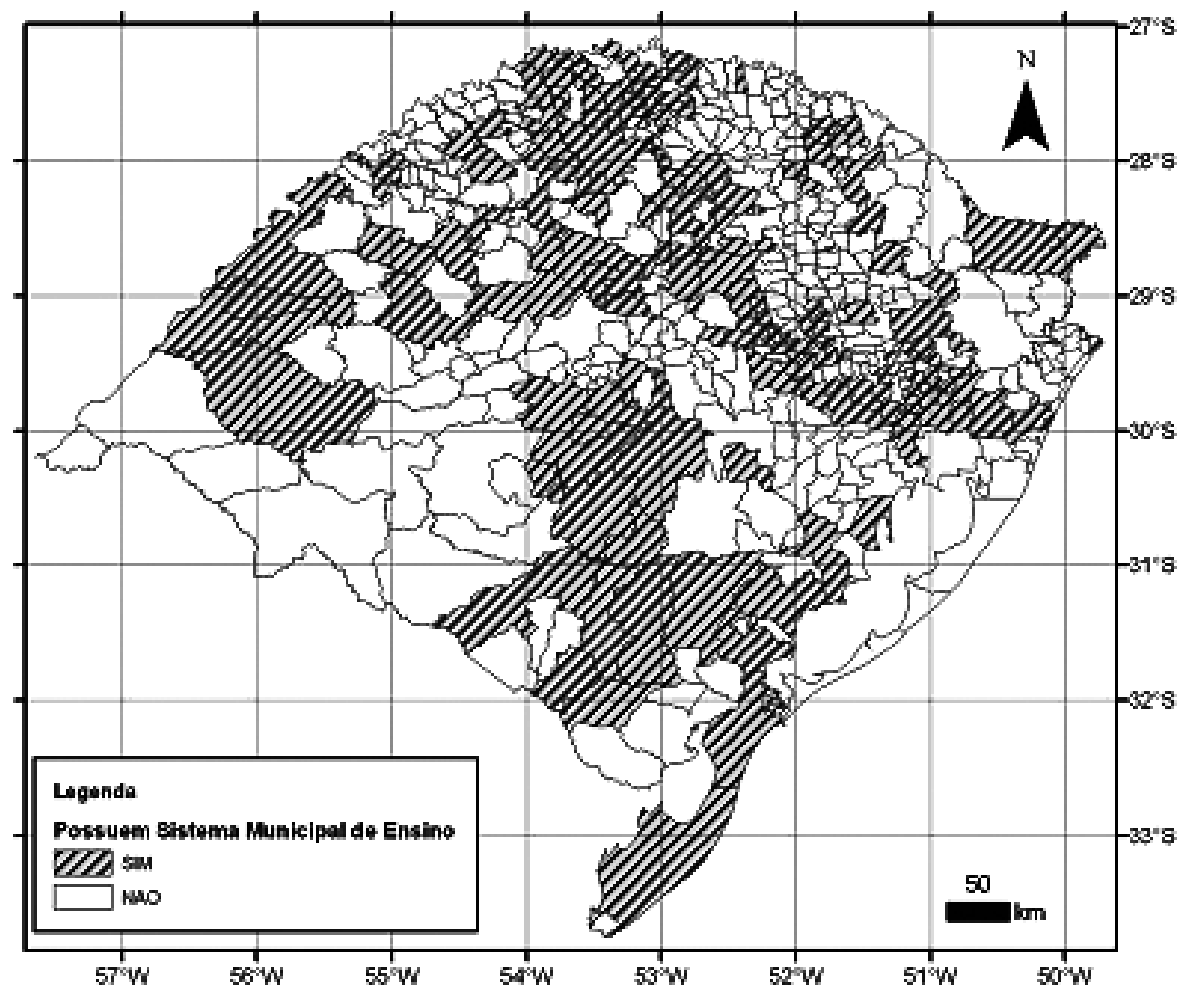

Mapa 1 - Municípios que criaram Sistemas Municipais de Ensino. Rio Grande do Sul (01/1997 -06/2007).

Fonte: Adaptado de IBGE (2005). 
A partir da Lei $n^{\circ} .9 .394$ (BRASIL, 1996), os municípios do RS começaram a constituir seus SME, apresentando, a cada gestão municipal, novo impulso no sentido de criação de sistemas. Assim, no período de 1997 a 2000, o primeiro ano foi o que mais contabilizou municípios criando leis de $S M E$, pois somam 16, 9, 15 e 10 municípios que, respectivamente, nesses anos, criaram SME. Entre 2001 a 2004, os municípios do RS demonstraram, especialmente nos dois primeiros anos, um grande impulso em direção a autonomia, responsabilização e estruturação da educação local, somando 36, 24, 9 e 6 municípios que, respectivamente, criaram SME no estado.

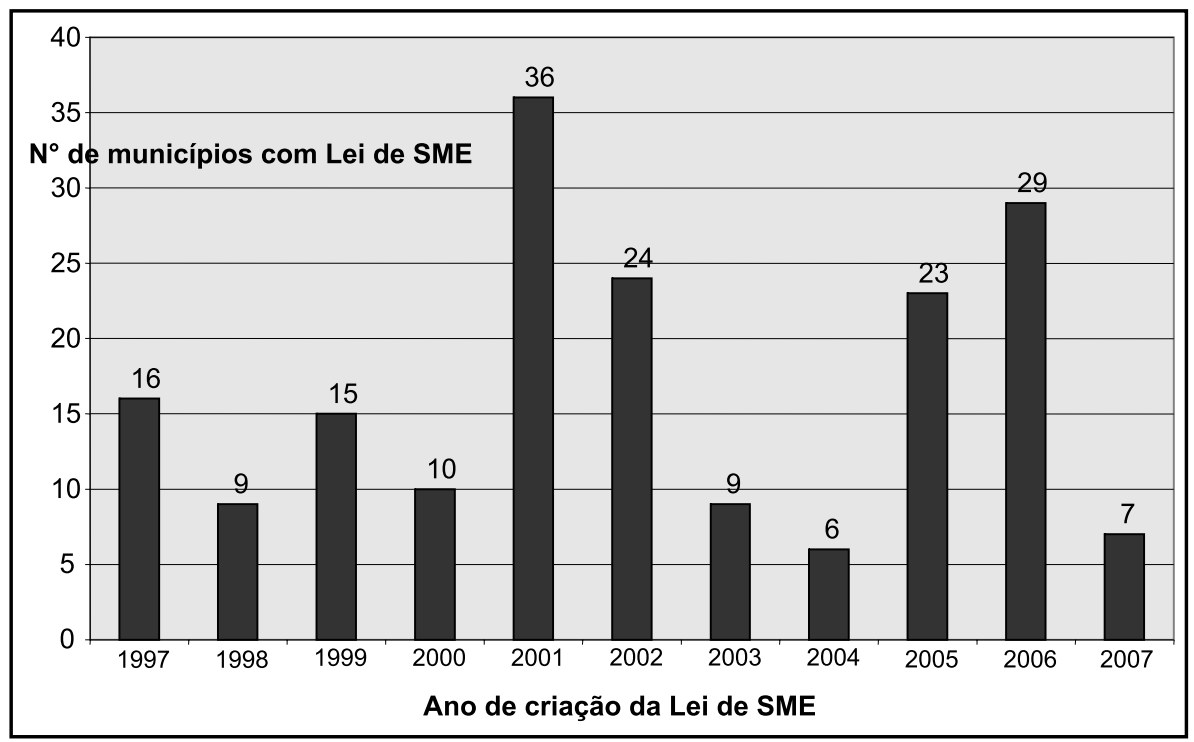

Gráfico 1 - Número de municípios com SME por ano de criação da Lei de sistema. Rio Grande do Sul (01/1997 - 06/2007).

Fonte: elaborado por Thum com dados da pesquisa (2007).

Pode-se, pois levantar a hipótese de que novos governos veem na criação de SME uma forma de afirmação de projetos políticos e/ou de inovação e diferenciação frente a propostas de governos anteriores. Pode também ser um dos motivos da criação do SME a vontade de libertar-se de normas de outras instâncias, do atendimento a recomendações do Conselho Estadual de Educação, muitas vezes avaliadas como muito exigentes ou rígidas. É necessário assinalar, entretanto que, a criação de SME não constitui ação passageira deste ou daquele governante, mas uma estrutura mais permanente em que o poder público, na instância municipal, assume responsabilidades estruturando a educação local. Por outro lado, criar o SME é uma etapa, mas há que consolidá-la e, para tanto, muita competência técnica, esforço político e recursos são necessários. 


\section{Grandes e pequenos municípios: dimensão das redes municipais de ensino}

Com a Constituição Federal (CF) de 1988 (BRASIL, 2003) assistimos a uma "onda municipalista". Entre 1996 e 2000 foram criados cerca de 25\% dos municipios hoje existentes. A CF de 1988 redefiniu o papel institucional, instaurou um novo pacto federativo entre os diferentes niveis de poder, com o que os municípios tiveram sua ação ampliada, obtendo um grau de autonomia até então inédito na história do Brasil e na comparação com outros paises federados (SOUZA; FARIA, 2005, p. 29-31).

No Rio Grande do Sul não foi diferente. Em 1809, eram apenas quatro municípios, Porto Alegre, Rio Pardo, Santo Antonio e Rio Grande. Em 1900, eram 64 municípios, em 1954, 112, em 1965, 232, em 1981, 233, em 1990, 333 chegando aos atuais 496 municipios. Pode-se falar, tal como Souza e Faria referiram-se à onda municipalista, como uma "onda emancipatória" no RS entre 1959 e 1965. Durante os anos sessenta, nos governos militares não houve praticamente emancipações. A lei era exigente sendo necessário uma população superior a dez mil habitantes, centro urbano com mais de duzentos prédios, além de atendimento a critérios de arrecadação. Houve um vácuo de emancipações entre 1967 e o inicio dos anos oitenta, podendo-se falar, no final dos anos oitenta, em nova onda emancipacionista.

Em qualquer das datas acima indicadas a designação é "municípios", desde os quatro existentes em 1809 até os 496 dos dias de hoje, como se todos fossem unidades municipais equivalentes entre si. Ademais o novo pacto federativo acima referido e instaurado com a CF de 1988 não diferencia municípios entre si, mas em relação às demais instâncias do Estado - nivel federal e estadual. Entretanto, afirmamos que a designação genérica "município" como que encobre e homogeiniza uma realidade muito diversificada do ponto de vista demográfico, de dimensões, de atividades econômicas e em termos educacionais.

A discussão de SME e das políticas educacionais municipais no RS exige a consideração de graus de diferenciação entre os 496 municípios, no caso do RS. Este alerta relaciona-se com a problematização formulada por Veiga em sua obra "Cidades imaginárias" sobre quão urbanizado é o Brasil. Pode-se indagar como incide nas políticas educacionais e mais especificamente na organização dos SME o debate acerca de questões urbanas e rurais, a diferenciação demográfica e territorial entre os municípios.

José Eli Veiga (2003, p. 47) afirma que o Brasil é menos urbano do que se calcula. Há "um oceano de municípios rurais", embora dados do ano 2000 indi-

Ensaio: aval. pol. públ. Educ., Rio de Janeiro, v. 17, n. 64, p. 397-420, jul./set. 2009 
quem que o país teria atingido $81,2 \%$ de urbanização. No Brasil toda a sede de município é considerada urbana, e o

caso extremo está no Rio Grande do Sul, onde a sede do municipio de União da Serra é uma 'cidade' na qual o Censo Demográfico de 2000 só encontrou 18 habitantes. [...] De um total de 5.507 sedes de município existentes em 2000, havia 1.176 com menos de 2.000 habitantes, 3.887 com menos de 10.000 (VEIGA, 2003, p. 32).

Há cidades de tamanho irrisório, apenas um aglomerado de agricultores e pessoas diretamente envolvidas com atividades primárias. Para o autor, há 455 municípios que são inequivocamente urbanos, onde se concentravam, em 2000,57\% da população nacional, situando-se 34\% em 12 aglomerações metropolitanas, 13\% em 37 aglomeraçoes não metropolitanas e 10\% em 77 centros urbanos. Em seu critério seriam de pequeno porte os municipios com simultaneamente menos de 50 mil habitantes e menos de 80 habitantes por km2 (VEIGA, 2003, p. 34).

Por outro lado, os atuais processos de reestruturação produtiva, de abertura comercial, de revolução digital e seus impactos nos transportes, comunicações e produção, de formação de blocos e a globalização trazem uma dinâmica diferenciada constituindo alguns municípios com um protagonismo impar. Principalmente os municípios de capitais em decorrência dos problemas a enfrentar e da amplitude das articulações se constituem, em suas formas de ação, como atores de relações internacionais. Embora tal protagonismo político e econômico, no plano internacional, se apresente, atualmente, apenas para algumas metrópoles brasileiras, o mesmo demanda autonomia para 0 âmbito municipal, com impacto em nosso modelo federativo (BARRET0, 2004; BARRETO; VIGEVANI, 2004). Impõe-se nesse contexto, de protagonismo das cidades que antes estavam imobilizadas sob a articulação da nação, a necessidade de retomada do modelo federativo brasileiro (BARRETO; VIGEVANI, 2004) sobre o qual incide o questionamento levantado por Ball (2001) de que os Estados Nação estariam perdendo sua autonomia política e econômica perante a influência e crescente amplitude das organizações supranacionais. Para Barreto e Vigevani (2004), os governos locais estão mais e mais assumindo a posição de sujeitos políticos no sistema internacional, interagindo com organismos internacionais multilaterais e de natureza intergovernamental, o que traz mais um elemento à crise do federalismo brasileiro, na qual o descompasso entre a possibilidade dos municípios se assumirem como entes políticos e os recursos políticos e institucionais capazes de implementá-los como tal, esvazia e dificulta a autonomia dos mesmos.

A questão educacional tem repercussão bastante diferenciada em grandes cidades.

Ensaio: aval. pol. públ. Educ., Rio de Janeiro, v. 17, n. 64, p. 397-420, jul./set. 2009 
Em geral as capitais não apresentaram indicadores satisfatórios em comparação com muitos municipios menores e com menos recursos. A partir dai vem se manifestando uma exigência maior para com os sistemas (conselhos, escolas e secretarias) de educação das capitais e dos municípios com população acima de 200 mil habitantes (FEITOSA, 2007, p. 37).

Em estudos recentes o MEC identificou um baixo desempenho no Índice de Desenvolvimento da Educação Básica (IDEB), em capitais e grandes cidades brasileiras frente ao que criou um grupo de trabalho "para que os gestores de 106 cidades com mais de 200 mil habitantes 'troquem experiências e debatam temas relacionados à gestão e às ações do Plano de Desenvolvimento da Educação'" (GRACIANO, 2007, p. 7).

Bravo (2007) debatendo gestão educacional e territorialização alerta para as repercussões da metropolização nas políticas educacionais e na gestão educacional. As regiões metropolitanas caracterizam cidades já constituídas com capacidade de catalisação numa região. Abrangem e integram um conjunto de municípios contíguos, em torno de um município polo, envolvendo articulações sociais, políticas e econômicas, bem como de serviços públicos e de infraestrutura comuns. São regiões de elevada densidade demográfica e alto grau de diversidade e de especialização. Nestas regiões há projetos (ou seria desejável que existissem) de desenvolvimento e planejamento integrados e os problemas, que anteriormente eram tratados como campo de ação de cada prefeitura em isolado, são tratados de forma global. Para o autor (BRAVO, 2007), é preciso levar em conta "áreas de transição" nas quais não há homogeneidade na definição dos aspectos sociais, econômicos e culturais, mas que são espaços que se incluem dentro da região metropolitana. As áreas de transição envolvem espaços em processos de "conurbação" - "encontro de duas ou mais cidades que ficam socialmente unidas, muito embora pela origem e pela administração, constituem-se cidades politicamente diferentes" (BRAVO, 2007, p. 45) -, "periferias" e "favelas" bem como "faixas territoriais não homogêneas" onde variam os elementos socioeconômicos e nas quais se apresentam aspectos ora do meio rural, ora do urbano (BRAVO, 2007, p. 12, 97). Conclui o autor pela necessidade de uma gestão educacional integrada para as regiões metropolitanas.

Barroso (1998, p. 14) ao discutir a autonomia das escolas adota a ideia de territorialização associando-a à descentralização:

0 conceito de territorialização é utilizado para significar uma grande diversidade de princípios, dispositivos e processos inovadores, no domínio da planificação, formulação de políticas educativas que, de um modo geral, vão no sentido de valorizar a afirmação dos poderes periféricos, a mobilização local dos atores e a contextualização da ação política.

Ensaio: aval. pol. públ. Educ., Rio de Janeiro, v. 17, n. 64, p. 397-420, jul./set. 2009 
Para Barroso (1998) é preciso abandonar a ênfase na homogeneidade das normas e dos processos, destacando a importância de contextualizar e localizar a política e ação educativa por meio da autonomia escolar, sensivel frente à heterogeneidade das formas e situações.

Este conjunto de considerações acerca do protagonismo político e econômico de municípios de regiões metropolitanas, da existência de "cidades imaginárias" e de zonas de conurbação, alerta-nos para a grande diversidade entre os municipios brasileiros. Conclui-se que a descentralização da educação, necessariamente, tem que ser uma política de base territorial, entendendo-se base territorial como a consideração de um conjunto de fatores diversificados de âmbito geográfico, cultural, social, econômico, demográfico e de outros tantos elementos incluindo infraestrutura, oportunidades de trabalho, condições de transporte. Em outras palavras, os SME relacionam-se e são formas de enquadramento territorial das políticas públicas de educação e as considerações acima - protagonismo internacional de certas regiões metropolitanas, áreas de transição, cidades imaginárias, o mar de municípios rurais, etc implicam sua constituição.

Embora o SME não seja uma proposta de estruturação apenas para escolas da rede municipal, seguramente municipios que têm rede muito diminuta precisam avaliar seriamente a necessidade e consequências de criar um SME próprio. Ampliação e qualificação de pessoal técnico, estruturas de apoio, acompanhamento e recursos financeiros, humanos e materiais são exigências decorrentes da criação de SME de forma a que este possa contribuir para desenvolver e responsavelmente qualificar a educação local.

Um levantamento do número de alunos das redes municipais do RS apresenta um cenário de prevalência de redes municipais muito pequenas. Há no Estado, 23 redes municipais com até 100 alunos matriculados e 215, com matrículas que variam de 101 a 500 alunos. No total $48 \%$ das redes municipais do RS somam, cada uma, até 500 matrículas. Ora, 500 matrículas equivalem a uma escola de porte pequeno ou médio.

Há 343 municípios no RS com redes públicas municipais com até 1.000 alunos, 0 que representa $69 \%$ do total de municípios do estado. Por outro lado, há oito municipios que são mantenedores de redes públicas numerosas, entre 20.000 e 60.000 alunos.

A disparidade entre o volume de alunos matriculados traz necessidades e problemáticas diferentes para a administração da educação municipal. Por outro lado a localização da população escolar acresce questões relacionadas à distância entre escolas e necessidade de deslocamento de alunos e/ou professores, dentre outras questões. 
A variação de matrículas em redes públicas municipais do RS é apresentada no Gráfico 2. Devido à disparidade, de sua composição, as redes municipais que somam mais do que 4.001 matrículas foram computadas em intervalos numéricos reorganizados, maiores do que os demais. De 4.001 matrículas a 60.000 matrículas articulamos os intervalos de apresentação, utilizando não mais o valor de 500 matrículas, mas de 1.000 em 1.000 matrículas. Esta decisão decorreu da constatação de que há poucos municípios com redes municipais muito grandes e, ao contrário, a grande maioria dos municipios rio-grandenses possuem redes de escolas com poucas matrículas. Ressaltamos que as informações referentes ao número de alunos matriculados nas redes municipais foram extraídos da tabela que o INEP disponibiliza demonstrando o cálculo do IDEB.

Esta informação é relevante, pois municípios, cuja rede de ensino é muito pequena, talvez a instalação de SME traga exigências descabidas em termos de recursos humanos, financeiros e estruturas administrativas. Assim instaura-se a dúvida: é possível pensar em criar SME num pequeno município cuja rede tenha menos de 100 alunos? Ou tenha 200 ou 300 alunos?

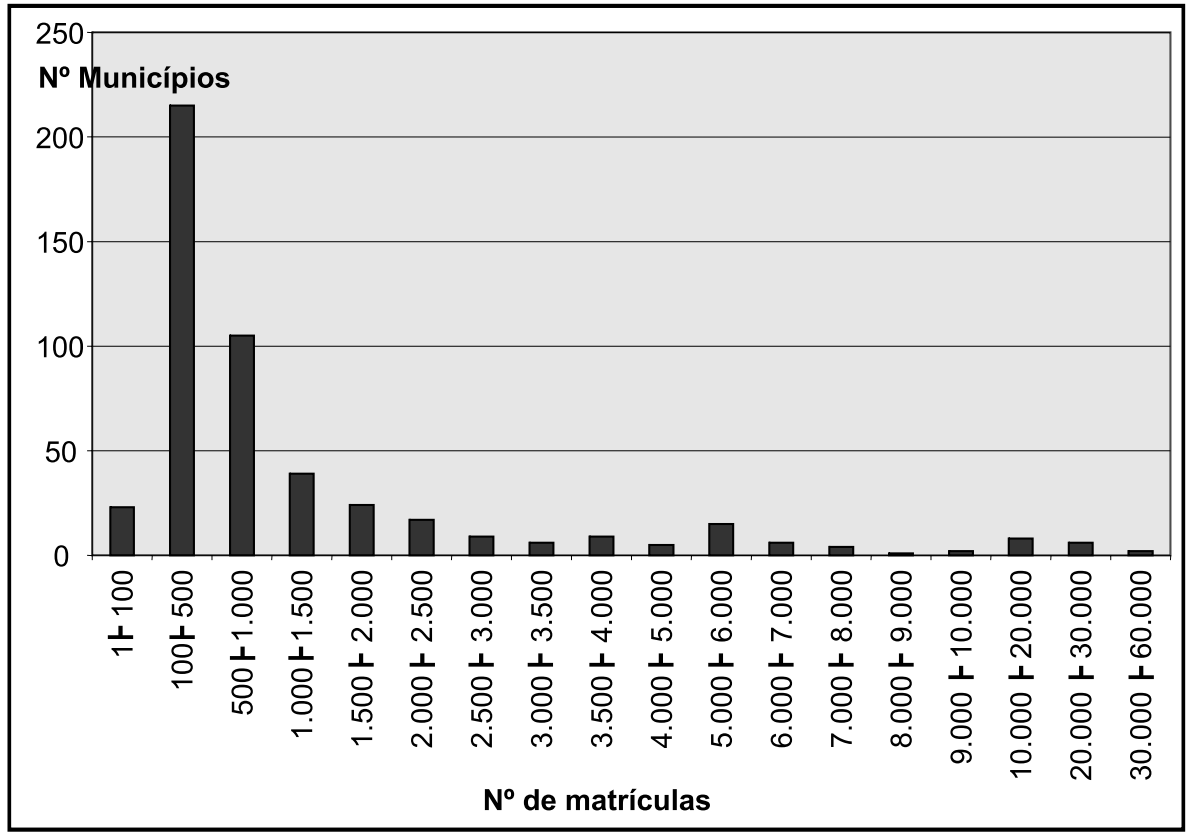

Gráfico 2 - Número de municípios por quantidade de matrículas na rede pública municipal. Rio Grande do Sul (2005).

Fonte: elaborado por Thum com dados da pesquisa (2007).

0 gráfico explicita que a maioria das redes municipais de ensino do RS é de pequeno porte, pois quase $70 \%$ delas chega a no máximo 1.000 matrículas.

Ensaio: aval. pol. públ. Educ., Rio de Janeiro, v. 17, n. 64, p. 397-420, jul./set. 2009 
É preciso registrar que a rede estadual muitas vezes contabiliza grande número de matrículas. Mesmo quando o montante de matrículas da rede municipal é expressiva, como por exemplo, Caxias do Sul, cujo conjunto de matrículas da rede municipal chega a 32.019, e Porto Alegre, que ascende a 56.928, é preciso analisar 0 atendimento da instância estadual. No caso destes dois municípios as matriculas nas redes municipais alcança o índice de 32\% e 20\% respectivamente, pois, ambas as redes somam juntas, um total de 97.385 e 277.419 alunos matriculados, respectivamente.

Portanto, a discussão de SME não pode ser feita de forma homogênea e padronizada. A criação de SME não pode ser tomada como norma mas precisa levar em conta as condições locais, ou seja, como argumentamos em outro espaço (WERLE; THUM; ANDRADE, 2008), para criar o SME há que levar em conta dimensões legal, pedagógica e organizativo-local.

\section{Inserção no Sistema Nacional de Avaliação da Educação Básica}

No Brasil, o Sistema Nacional de Avaliação da Educação Básica (SAEB), existe desde o final dos anos oitenta consolidando-se a partir de 1995. 0 SAEB é uma avaliação amostral com abrangência em todo o território nacional, cujo objetivo é verificar as competências de leitura e resolução de problemas matemáticos de alunos da $4^{\text {a }}$. e da $8^{a}$. séries do ensino fundamental e $3^{\circ}$. do ensino médio. Com o SAEB inaugura-se um sistema de informações sobre a qualidade da educação básica dando um salto no tipo de informações oferecidas pelas estatísticas educacionais que se detinham sobre acesso e fluxo (FRANCO; ALVES; BONAMINO, 2007).

A partir de 2005 outros instrumentos são introduzidos na sistemática nacional da avaliação da educação básica. Nesta data inicia-se a Prova Brasil, aplicada em escolas urbanas com mais de 30 alunos nas $4^{\text {a }}$. e $8^{\text {a }}$. séries do ensino fundamental, abrangendo 5.398 municípios de todas as unidades da federação adotando o mesmo marco teórico, procedimentos e técnicas do SAEB (INEP, 2005).

A forma de apresentação dos dados destas duas modalidades de avaliação variam conforme seus objetivos. As informações do Saeb são apresentadas por unidade da federação e por capitais, além da situação geral do pais, informando acerca da "população" de alunos das séries avaliadas. A Prova Brasil informa mais detalhadamente apresentando dados por escola, por rede, município, unidade da federação, bem como sobre a situação geral de todo o país.

A Lei no. 9.394 (BRASIL, 1996), reafirma estes procedimentos na medida em que responsabiliza as diferentes instâncias do Estado pela inserção de suas redes escola-

Ensaio: aval. pol. públ. Educ., Rio de Janeiro, v. 17, n. 64, p. 397-420, jul./set. 2009 
res no sistema nacional de avaliação da educação. Para tanto, em seu artigo $9^{\circ}$., a LDB apresenta as incumbências da União, dentre as quais indica a de:

assegurar processo nacional de avaliação do rendimento escolar no ensino fundamental, médio e superior, em colaboração com os sistemas de ensino, objetivando a definição de prioridades e a melhoria da qualidade do ensino;

De acordo com Franco, Alves e Bonamino (2007, p. 1003) neste trecho a LDB orienta-se por dois tipos de racionalidade, a técnica e a substantiva, pois a legislação

explicita como objetivos da avaliação do rendimento dos alunos contribuições para a definição de prioridades - aspecto relacionado com políticas baseadas em evidências, no veio da racionalidade técnica - e a melhoria da qualidade do ensino, aspecto relacionado com racionalidade relativa aos fins ou "racionalidade substantiva.

Por outro lado, não se pode esquecer que a LDB (BRASIL, 1996), em seu artigo 87, indica, com clareza, o papel da instância municipal, especificando que cada município e, supletivamente, o Estado e a União, deverá, dentre outras ações "integrar todos os estabelecimentos de ensino fundamental do seu território ao sistema nacional de avaliação do rendimento escolar". Portanto o processo nacional de avaliação da educação básica deverá envolver, em regime de colaboração, as diferentes instâncias do estado tendo em vista o estabelecimento de prioridades e a melhoria da qualidade do ensino.

Há, por conseguinte, dois aspectos que comprometem os municípios com a avaliação externa de larga escala: a Lei de Diretrizes e Bases da Educação Nacional (BRASIL, 1996) e a processualidade dos mecanismos de avaliação externa de larga escala. Nesta processualidade se incluem o SAEB e a Prova Brasil. 0 primeiro, há vinte anos em funcionamento sob a liderança do INEP, coleta dados diretamente nas redes públicas e em estabelecimentos privados, incidindo em todas as redes e em todos os estados da federação. A partir de 2005 a Prova Brasil torna-se mais uma evidência de procedimento avaliativo articulado pela instância federal focado nas diferentes redes públicas e em escolas urbanas, a qual se reforça ainda mais, a partir de 2007, com o IDEB.

As leis de $\mathrm{SME}$, entretanto, pouco referem esta responsabilidade de integração universal das escolas públicas aos sistemas de avaliação de larga escala em vigência no país. A maioria das leis de SME do RS nem sequer menciona a inserção das escolas do município em sistemas de avaliação de larga escola.

Dentre o conjunto das 25 associações de municípios que agregam municípios no RS, apenas 13 delas têm algum município cuja lei de criação do SME menciona este tipo de avaliação.

Ensaio: aval. pol. públ. Educ., Rio de Janeiro, v. 17, n. 64, p. 397-420, jul./set. 2009 


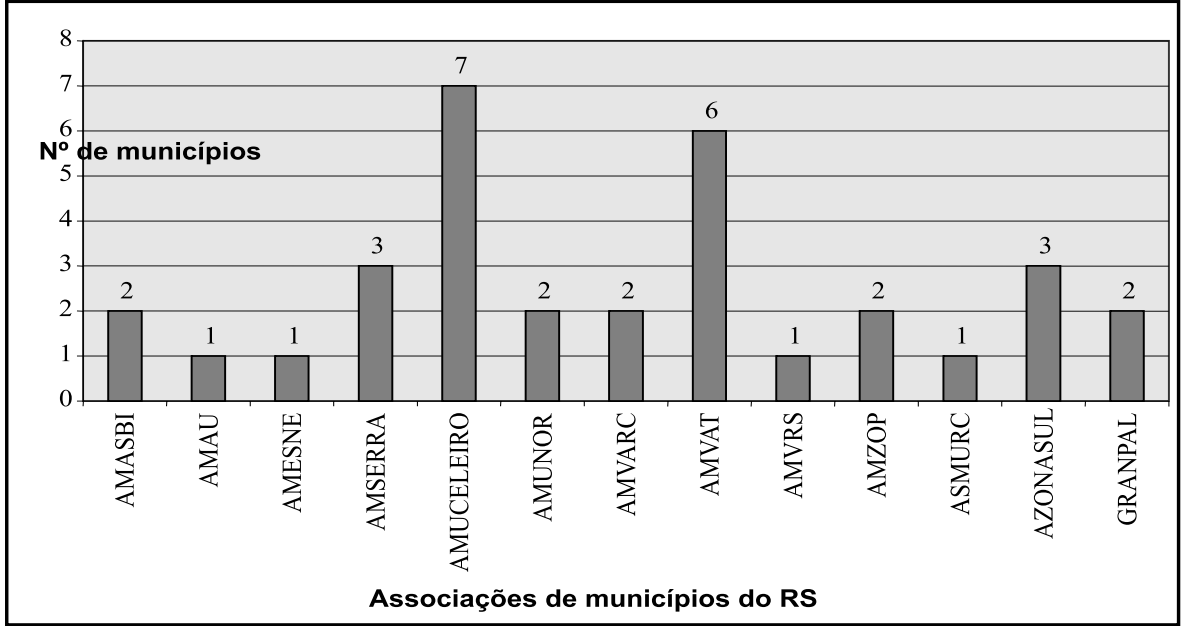

Gráfico 3 - Municípios de acordo com sua Associação que mencionam o tema Sistema Nacional de Avaliação em sua lei de SME. Rio Grande do Sul (01/1997-06/2007). Fonte: elaborado por Thum com dados da pesquisa (2007).

Por outro lado poder-se-ia pensar que os SME que tivessem sido criados mais recentemente contemplariam mais amiúde a questão da avaliação externa da educação básica. Esta hipótese, entretanto, não se confirma.

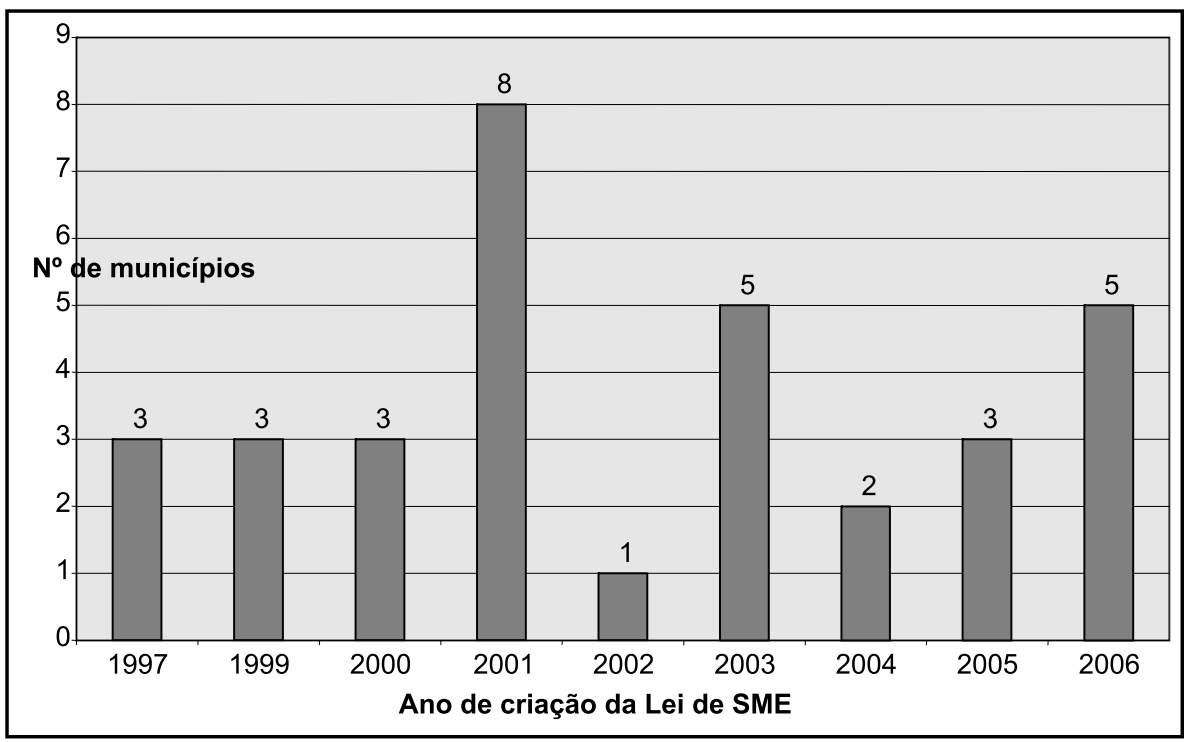

Gráfico 4 - Municípios que no SME mencionam Sistema Nacional de Avaliação por ano de criação da Lei. Rio Grande do Sul (01/1997-06/2007).

Fonte: elaborado por Thum com dados da pesquisa (2007).

Ensaio: aval. pol. públ. Educ., Rio de Janeiro, v. 17, n. 64, p. 397-420, jul./set. 2009 
Dentre as 184 leis analisadas, apenas 10\% faz referência clara e direta ao sistema externo de avaliação, em geral adotando a seguinte formulação:

- O Município deverá: [...] IV. integrar os estabelecimentos de ensino fundamental do seu território ao Sistema Nacional de Avaliação do Rendimento Escolar.

- Compete ao Sistema Municipal de Ensino, em regime de colaboração, com o Sistema Estadual de Ensino e em conformidade com a política nacional de educação definida pela União, o que segue: .... IV - participar do processo nacional de avaliação do rendimento escolar no ensino fundamental e médio, objetivando a definição de prioridades e a melhoria da qualidade do ensino, assegurado pela União (art. $9^{\circ}$, inciso Vl);

- Serão empreendidos esforços constantes objetivando: ... II - a mantença dos estabelecimentos municipais de Ensino Fundamental integrados ao sistema nacional de avaliação do rendimento escolar.

De fato estas referências não detalham estratégias, processos e responsáveis no âmbito do município, não indicam como serão eleitas as necessidades, ou como deverão ser elas priorizadas para superar as deficiências identificadas pela avaliação. Nas leis de SME não há indicativos de procedimentos preparatórios à aplicação dos testes nem como e que setor da Secretaria Municipal será responsável pela avaliação de larga escala. Os textos legais não remetem a outras leis ou regulamentações para definir papéis do executivo, do CME e demais colegiados, no trabalho a ser feito com os resultados da avaliação, nem o protagonismo da secretaria municipal de educação no apoio às escolas para a melhoria da educação local, a partir da avaliação. Os textos não propõem nem remetem a processualidades de discussão com a comunidade escolar, pais, professores e alunos, a respeito dos dados da avaliação. Ora, como lembra Libâneo (2004, p. 238), citando Casassus

Embora sejam os alunos os que respondem a provas e questionários, na realidade não são os alunos que são avaliados. 0 que se avalia é o rendimento do sistema por meio das respostas dos alunos. Então, as interrogações dos estudos deveriam consistentemente orientar-se, não às pessoas que são os alunos, mas ao sistema no qual estão inseridos os alunos.

Os municípios que criam seus próprios SME precisariam, necessariamente, assumir conjuntamente com as instâncias promotoras da avaliação externa de larga escala, o processo e os resultados das avaliações. Por outro lado precisariam comprometer-se em trabalhar os resultados de forma a avaliar as suas próprias políticas, as condições de funcionamento de suas escolas, o apoio e as condições de formação continuada dos seus professores.

Entretanto, ao que parece as leis de SME não se deixam interrogar pela instigação da LDB (BRASIL, 1996) à integração dos municípios ao sistema nacional de avaliação da educação básica. Várias leis de SME repetem as declarações da LDB quanto à avaliação de larga escala sem identificar seus desdobramentos para o SME.

Ensaio: aval. pol. públ. Educ., Rio de Janeiro, v. 17, n. 64, p. 397-420, jul./set. 2009 
A formulação "mantença dos estabelecimentos municipais de ensino fundamental integrados ao sistema nacional de avaliação do rendimento escolar", que é um dos únicos detalhamentos encontrados nos documentos analisados, é evidentemente muito restrita, frente ao grande espectro de ações possiveis e demandadas por um sistema de avaliação externa, tão dispendioso para os cofres públicos da União, principalmente, e tido como importante instrumento de transparência da ação do Estado nas políticas públicas educacionais. Os sistemas de avaliação de larga escala postulam, para as unidades escolares, uma posição com base no mérito, que leva a comparações, definida pela resposta de seus alunos a testes padronizados. 0 que não transparece nas leis de SME é que tais dados obtidos apenas serão úteis se subsidiarem e forem relacionados à gestão do sistema, da escola e ao trabalho do professor. Portanto, seria necessário que as secretarias dos municípios, como mantenedoras das escolas públicas avaliadas, tivessem explicitado seus compromissos para com as escolas de sua rede, os gestores e o corpo docente, no sentido de desencadear processos voltados para a equidade e ajuda a cada unidade escolar, com a finalidade de alcançar melhor nivel de qualidade. Esta observação se embasa principalmente nas prescrições da Lei n. 9.394 (BRASIL, 1996) que, em seu artigo 11 indica aos municípios integrarem-se às políticas e planos educacionais dos estados e da União, assim como exercer ação redistributiva em relação às suas escolas.

A ação redistributiva que os municípios devem realizar junto a suas escolas poderia ser subsidiada pelos resultados da avaliação externa de larga escala. Assim, as escolas de toda a rede deveriam ter suas condições de funcionamento e seu contexto estudados aprofundadamente de forma a identificar situações de carência e desencadear ações redistributivas de parte do executivo municipal, tendo em vista equalizar a oferta educacional na rede.

Algumas leis de SME trazem uma referência diferenciada à avaliação embora não utilizem a terminologia "inserção no sistema nacional de avaliação da educação básica". São exemplificativos os trechos abaixo:

- A Secretaria Municipal de Educação é o órgão que exerce as atribuições do Poder Público municipal em matéria de educação, cabendo-lhe, em especial: [...] A avaliação, do desempenho da escola, dos professores, dos alunos e diferentes segmentos que compõe a instituição escolar realizada sistematicamente, sob a coordenação da direção da escola, com a participação do Conselho Municipal de Educação, pais, alunos e funcionários, abrangerá diversos fatores que determinam a qualidade do ensino. Esta avaliação deverá ser registrada em ata especifica com assinatura dos presentes. [...] A avaliação realizada sistematicamente, sob a coordenação da Secretaria Municipal de Educação, referente aos índices de desempenho, acesso, permanência e outros fatores que determinam a qualidade do en- 
sino serão registrados na Proposta Político-Pedagógica da Secretaria Municipal de Educação, dados estes que servirão de referência para o trabalho de orientação e supervisão realizado pela mesma.

- 0 projeto político-pedagógico e o regimento escolar, além das disposições legais sobre a educação escolar do Município, constituir-se-ão no referencial para a autorização de funcionamento e avaliação de qualidade de ensino, e para fiscalização das atividades dos estabelecimentos de ensino, de competência do Conselho Municipal e da Secretaria Municipal de Educação e Esporte.

No primeiro caso a avaliação está relacionada ao projeto pedagógico da secretaria de educação e é o executivo municipal, por meio da secretaria municipal de educação que realizará a avaliação da escola e de cada segmento, envolvendo para tanto a direção dos estabelecimentos de ensino e o Conselho Municipal de Educação com foco na qualidade de ensino entendida como acesso, permanência e alcance de índices de desempenho. No segundo caso, igualmente o Projeto Político-Pedagógico (PPP) é referido tal como o regimento. Estes, entretanto, são aqui dimensionados para 0 âmbito escolar e não mais no de secretaria municipal de educação e o que nestes documentos - PPP e Regimento - estiver firmado, servirá de critério para a avaliação da qualidade do ensino. Em ambos os casos não há referência explicita na lei do SME sobre a integração no sistema nacional de avaliação da educação básica.

Referindo-se à metodologia de análise que adotamos no projeto de pesquisa, encontramos $8 \%$ das leis que criam SME com formulações tenuemente indicativas da consideração de processos de avaliação, o que não as caracteriza como intencionalmente inseridas no sistema nacional de avaliação da educação básica. Estas poucas leis que assim postulam a avaliação, a indicam como competência do Conselho Municipal de Educação que deverá proceder à avaliação da realidade local:

- São competências do Conselho Municipal de Educação: [...] a avaliação da realidade educacional do Município e proposição de medidas aos Poderes Públicos para a melhoria do fluxo e do rendimento escolar;

- São fins da educação: [...] desenvolvimento de sistemas de informação e avaliação.

- A avaliação institucional será realizada sistematicamente sob a coordenação da Secretaria de Educação, com a participação do Conselho Municipal de Educação e abrangerá os diversos fatores que determinam a qualidade do ensino.

\section{Elementos conclusivos}

A leitura e apreensão da autonomia municipal explicitada por meio da criação de SME é uma forma de dimensionar a descentralização da educação brasileira. As leis de SME podem ajudar a compreender até que ponto os diferentes temas das politicas educacionais estão sendo consideradas e absorvidas nos diferentes pontos do pais. Este estudo não permite afirmar que o SME é um contexto que acolhe as

Ensaio: aval. pol. públ. Educ., Rio de Janeiro, v. 17, n. 64, p. 397-420, jul./set. 2009 
propostas de avaliação de larga escala. Ao contrário, estas propostas passam ao largo das iniciativas de criação de SME, sugerindo que o tema das avaliações externas de larga escala da educação básica não se articula por meio de espaços de colaboração e diálogo entre as instâncias do Estado.

À pergunta, quais as formulações peculiares e especificadoras para o tema da avaliação externa de larga escala da educação básica criadas nos sistemas municipais de ensino, a resposta é: inexistem tais formulações. Os dados desta pesquisa indicam que não há, até a data deste estudo, leis de SME que apresentem esta discriminação. Em algumas leis há a transcrição lacônica da LDB, pois a formulação "mantença das escolas no sistema de avaliação" é muito vaga - apenas informa que o municipio deixa-se avaliar, mas não o que ele fará com os dados dai obtidos. Reitera-se que a constituição do SME tem o papel de estruturar a educação no espaço do município e em tal documento de política pública as preocupações com avaliação e acompanhamento externo da ação da escola básica são inexistentes ou fracamente e não extensiva e criativamente referidas, e, portanto não enfrentadas. Assim podese dizer que as leis de SME não são documentos estruturadores da posição da instância municipal quanto à questão da avaliação de larga escala. A instância municipal no que toca aos textos das leis de SME mostra-se não sensível a políticas com base em evidências. Ou seja, no contexto das leis de SME, não há indícios de estruturação de mecanismos e de processos de racionalidade técnica com referência ao tema da avaliação externa de larga escala.

Cabe lembrar que, embora as leis de SME não explicitem a inserção do município no sistema nacional de avaliação da educação básica, as escolas públicas em geral e as redes de ensino municipais são o espaço em que tais avaliações se processam. É fato de que há, no mínimo quinze anos, os sistemas de ensino, vêm sendo envolvidos em avaliações de larga escala, como, por exemplo, o SAEB, o que, hoje se acentua, especialmente a partir do Plano de Desenvolvimento da Educação (PDE), de abril de 2007, que institui o IDEB. Entretanto, as leis que criam os SME desconhecem ou quando muito, pouco incluem, o debate da avaliação de larga escala e da avaliação da qualidade do ensino mediante processos externos de acompanhamento, avaliação e diagnóstico da escola e dos sistemas de ensino.

Assim, o tema da avaliação externa de larga escala lança sombras sobre a afirmativa de que as políticas não são um processo formal de cumprimento de regras e determinações que são geradas em outras instâncias. Embora a avaliação externa da educação básica seja uma realidade forte e presente em escolas públicas de zonas urbanas (para se falar apenas na Prova Brasil) é uma questão em geral não contemplada e desdobrada nas leis de SME. Isto sugere que a criação de leis de SME não mapeia e institucionaliza todas as ações que envolvem a educação escolar local. Pode-se levantar a hipótese de que a institucionalização de políticas concebidas/ 
promovidas em outras instâncias - caso da avaliação externa SAEB e Prova Brasil, na instância federal - impõem-se por processos de ingerência (WERLE, 2005) que se sobrepõem aos de descentralização e de exercício do poder local.

Ingerência e descentralização, imposição e autonomia local se mesclam produzindo uma situação hibrida (BARROSO, 2003) que complexifica a interpretação do cenário das politicas educacionais brasileiras.

Os municipios mostram-se permeáveis (WERLE, 2005) às políticas concebidas na instância federal muitas das quais se impõem pela associação entre dois aspectos: adesão a propostas do governo federal e à liberação de recursos (que geralmente exigem uma contra-partida dos municípios). Melhor dizendo, tais políticas não são propostas, amadurecidas e refletidas a partir da realidade local, mas "aterrizam" na realidade escolar municipal sem prévia negociação ou diálogo mediador que poderia ser gerado se houvesse efetivo regime de colaboração. Embora a instância municipal exercite seu poder e autonomia pela criação de SME há temas de política educacional que thes escapa ou que são negados pois alijados e silenciados em contextos locais de formulação de políticas.

Os municípios brasileiros são muito diferenciados entre si, havendo um mar de municipios rurais caracterizando grande parte dos municípios brasileiros. A pouca adesão e ausência de ressignificação da avaliação externa de larga escala nas leis de criação de SME é sugestiva e bastante comum na instância municipal. Sugestiva de que os municípios estão mais voltados para acolher e exercitar outros temas que eles contemplam com muito mais frequência produzindo desdobramentos inovadores e peculiares às condições locais e com eles exercitando o poder local. Como exemplo pode-se citar a eleição de diretores (WERLE; MANTAY; ANDRADE, 2009) e a importância atribuida aos profissionais da educação (WERLE, 2009), dentre outros (WERLE, 2008). Sugestiva no que se refere a quanto o regime de colaboração precisa avançar, pois o processo nacional de avaliação do rendimento escolar deve ser assegurado no contexto de um regime de colaboração sem desconhecer a possibilidade de cada município organizar o seu SME.

Se, entretanto, estas leis não expressam grande adesão ao sistema nacional de avaliação da educação básica, não há motivo para recentralizar no âmbito do governo federal as políticas educacionais e fazer tábula-rasa das pretensões e ações dos municípios se auto-organizarem estruturando seu Sistema Municipal de Ensino. Os municípios que criaram seus sistemas municipais de ensino exercem sua autonomia e, de forma ativa e cidadã chamam a si a responsabilidade de estruturar e instituir a educação local, o que é um valor importante que merece ser preservado e desenvolvido. 


\section{Referências}

BALL, S. J. Cidadania global, consumo e política educacional. In: SILVA, L. H. (Org.). A escola cidadã no contexto globalizado. Petrópolis: Vozes, 1998.

Diretrizes políticas globais e relações políticas locais em educação.

Currículo sem Fronteiras, [S.I.], v.1, n.2, p. 99-116, jul./dez. 2001. Disponível em: <http://www.curriculosemfronteiras.org/index.htm>. Acesso em: 3 set. 2009.

BALL, S. J. Mercados educacionais, escolha e classe social: mercado como estratégia de classe. In: GENTILE, P. (Org.). Pedagogia da exc/usão: critica ao neoliberalismo em educaçao. Petrópolis: Vozes, 1995.

BARRETO, M. I. Inserção internacional de governos locais. Teoria e Debate, São Paulo, v.17, n. 59, p. 12-16, ago./set. 2004.

BARRETO, M. I.; VIGEVANI, T. Cenário global e o espaço de intervenção dos governos locais. In: MARTINS, A. M.; OLIVEIRA, C.; BUENO, M. S. S. Descentralização do Estado e municipalização do ensino: problemas e perspectivas. Rio de Janeiro: DPCA, 2004.

BARROSO, J. 0 reforço da autonomia das escolas e a flexibilização da gestão escolar em Portugal. In: FERREIRA, N. S. C. F. Gestão democrática da educação: atuais tendências, novos desafios. São Paulo: Cortez, 1998.

Regulação e desregulação nas políticas educativas: tendências emergentes em estudos de educação comparada. In: BARROSO, J. (Org.). $A$ escola pública: regulação, desregulação, privatização. Porto, PT: ASA, 2003.

BRASIL. Constituição (1988). Constituição da República Federativa do Brasil de 1988. Brasilia, DF, 2003. Disponivel em: <www.planalto.gov.br/.../constituicao/ constituiçao.htm >. Acesso em: 3 set. 2009.

Lei $n^{\circ} .9 .394$, de 20 de dezembro de 1996. Estabelece as diretrizes e bases da educação nacional. Diário Oficial [da República Federativa do Brasil], Brasilia, DF, 23 dez. 1996.

BRAVO, I. Gestão educacional no contexto da territorialização. Campinas, SP: Alínea, 2007.

CONSELHO NACIONAL DE EDUCAÇÃO (Brasil). Câmara de Educação Básica. Parecer $n^{\circ}$. 30, de 12 de setembro de 2000. Define sistema de ensino dentro do ordenamento jurídico-administrativo, tendo-se como referência a organização da educação nacional. Diário Oficial [da República Federativa do Brasil], Brasilia, DF, 6 out. 2000. 
CUNHA, L. A. A reorganização do campo educacional: as conferências de educação. Educação e Sociedade, Campinas, SP, v. 3, n. 9, p. 3-48, maio 1981.

FEITOSA, R. M. M. A utilização dos indicadores na gestão municipal. In: GRACIANO, M. (Coord.). O Plano de Desenvolvimento da Educação (PDE). São Paulo: Ação Educativa, 2007.

FRANCO, C.; ALVES, F.; BONAMINO, A. Qualidade do ensino fundamental: políticas, suas possibilidades, seus limites. Educação e Sociedade, Campinas, SP, v. 28, n. 100 , p. $989-1014$, out. 2007. Especial.

FREY, K. Políticas públicas: um debate conceitual e reflexões referentes à prática da análise de políticas públicas no Brasil. Planejamento e políticas públicas, Brasilia, DF, n. 21, p. 211-259, jun. 2000.

GRACIANO, M. (Coord.). O Plano de Desenvo/vimento da Educação (PDE). São Paulo: Ação Educativa, 2007.

INEP. Prova Brasil. Brasilia, DF, 2005. Disponivel em: <http://www.inep.gov.br>. Acesso em: 3 set. 2009.

LIBÂNEO, J. C. Organização e gestão da escola: teoria e prática. Goiânia: Alternativa, 2004.

LIMA, L. A escola como organização educativa. São Paulo: Cortez, 2001.

LOPES, A. C. Políticas curriculares: continuidade ou mudança de rumos?. Revista Brasileira de Educação, Rio de Janeiro, n. 26, p. 109-118, maio/ago. 2004.

MAINARDES, J. Abordagem do ciclo de políticas: uma contribuição para a análise de políticas educacionais Educação e Sociedade, Campinas, SP, v. 27, n. 4, p. 4794, 2006.

SOUZA, D. B.; FARIA, L. C. M. Politica, gestão e financiamento de sistemas municipais públicos de educação no Brasil: bibliografia analítica (1996-2002). São Paulo: Xamã; Niterói: Intertexto, 2005.

STROMQUIST, N. P. Políticas públicas de Estado e equidade de gênero. Revista Brasileira de Educação, Rio de Janeiro, n. 1, p. 27-49, jan./fev./mar./abr. 1996.

TEIXEIRA, L. H. Conselhos Municipais de Educação: autonomia e democratização do ensino. Cadernos de Pesquisa, São Paulo, v. 34, n. 123, p. 691-708, set./dez. 2004. 
VEIGA, J. E. Cidades imaginárias: o Brasil é menos urbano do que se calcula. 2. ed. Campinas, SP: Autores Associados, 2003.

WERLE, F. O. C. O nacional e o local: ingerência e permeabilidade na educação brasileira. Bragança Paulista, SP: EDUSF, 2005.

Organización de los sistemas de educación municipales en Brasil. In: CONGRESSO INTERUNIVERSITÁRIO DE ORGANIZAÇÃO DE INSTITUIÇÕES EDUCATIVA, 10., 2008, Barcelona. Anais... Barcelona, 2008.

Politicas educacionais da instância municipal: focando a formação e a valorização docente. In: $\mathrm{CENCl}, \mathrm{A}$. (Org.). Sobre filosofia e educação:

racionalidade, diversidade e formação pedagógica. ljui, RS: Edijui, 2009. No prelo.

WERLE, F. 0. C.; MANTAY, C.; ANDRADE, A. C. Direção de escola básica em perspectiva municipal. Educação: revista da PUCRS, Porto Alegre, 2009. No prelo. $\therefore$ THUM, A. B.; ANDRADE, A. C. O Sistema Municipal de Ensino e suas implicações para a atuação do Conselho Municipal de Educação. Revista Brasileira de Política e Administração da Educação, Niterói, RJ, v. 24, n. 1, p. 79-109, jan./ abr. 2008.

Recebido em: 23/04/2009

Aceito para publicação em: 23/07/2009 